\title{
A new species of Hexapinus Manning \& Holthuis, 1981 (Decapoda: Brachyura: Hexapodidae) from Hatoma Island, Ryukyu Islands, Japan
}

Tohru Naruse

\begin{abstract}
A new species of Hexapinus (Hexapodidae) is described from Hatoma Island, Ryukyu Islands, Japan. Hexapinus patuma, new species, is morphologically close to H. latus Rahayu \& Ng, 2014, but can be distinguished by the structures of the carapace and third maxilliped, as well as the degree of setation of ambulatory legs.
\end{abstract}

LSID urn:1sid:zoobank.org:pub:5743D245-C07D-4953-920A-CD781534F1F3

Key words: Taxonomy, new species, burrower, sandy bottom, yabbie pump

\section{Introduction}

Systematics of the family Hexapodidae Miers, 1886, have been substantially revised by Manning \& Holthuis (1981) and Rahayu \& $\mathrm{Ng}$ (2014), and recent studies have added more new taxa (Ng \& Rahayu, 2015; Velip \& Rivonker, 2014; Rahayu \& Widyastuti, 2018; Ng \& Wong, 2019); the family currently contains 44 recent species in 16 genera. Among these taxa, eight species in five genera have been recorded from Japan: Hexalaughlia orientalis (Rathbun, 1909), Hexapinus latipes (De Haan, 1835), H. simplex Rahayu \& Ng, 2014, Hexaplax megalops Doflein, 1904, Mariaplax chenae Rahayu \& Ng, 2014, M. narusei Rahayu \& Ng, 2014, M. ourabay Rahayu \& Ng, 2014, and Rayapinus maenosonoi Rahayu \& Ng, 2014 (De Haan, 1835; Matsuo, 1971; Sakai, 1939; 1965; 1976; Rahayu \& Ng, 2014; Naruse et al., 2017).

Recent field work by the author collected a good number of hexapodids, including undescribed species, from subtidal environments with the help of SCUBA and yabbie pump (see Naruse et al., 2017). The present study de- scribes one new species of Hexapinus Manning \& Holthuis, 1981, collected from Hatoma Island, Yaeyama Islands, Ryukyu Islands, Japan. Material examined is deposited in the Ryukyu University Museum, Fujukan (RUMF), University of the Ryukyus, Japan. Measurements, in millimetres, are indicated as carapace length $(\mathrm{CL}) \times$ carapace width $(\mathrm{CW})$. Other abbreviations used in this paper are as follows: G1, 2, male first and second gonopod; $\operatorname{mxp} 3$, third maxilliped; P2-4, second to fourth pereopods, respectively.

\section{Taxonomy}

Family Hexapodidae Miers, 1886

Hexapinus Manning \& Holthuis, 1981

Hexapinus patuma, new species

LSID urn:lsid:zoobank.org:act:47005568-

D106-429C-A989-6979C60B5944

[New Japanese name: Patuma-mutsuashi-gani]

(Figs. 1-4)

\section{Material examined}

Holotype, RUMF-ZC-5835, male, 4.9× $9.5 \mathrm{~mm}$, in SE reef of Hatoma Island, Yaeyama 


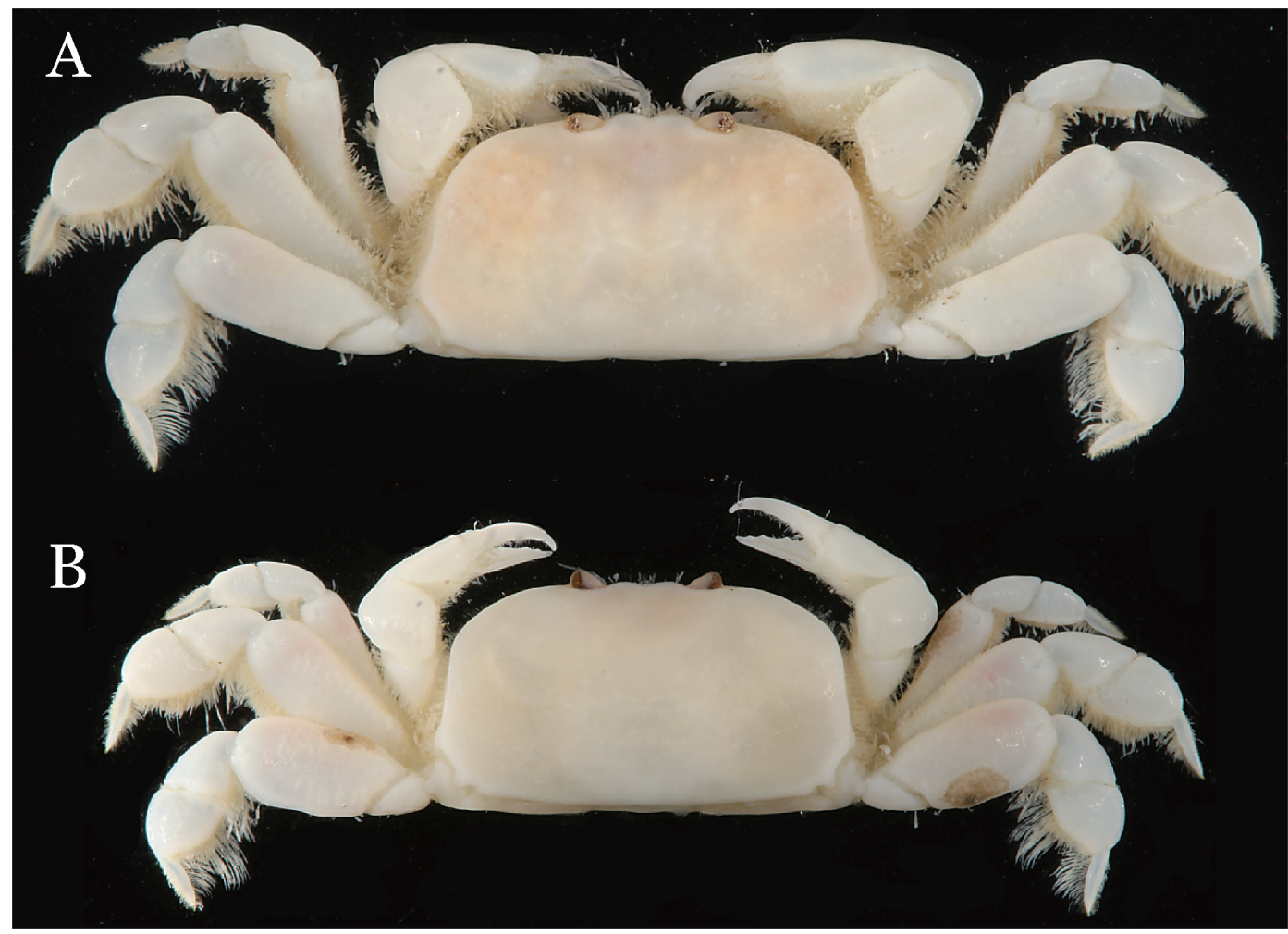

Fig. 1. Dorsal habitus of Hexapinus patuma, new species. A, holotype male, RUMF-ZC-5835, 4.9 $\times 9.5$ mm; B, paratype female, RUMF-ZC-5836, $4.6 \times 8.7 \mathrm{~mm}$. A and B are isometric.

Islands, Ryukyu Islands, Japan, 24.457048, 123.833223, ca. - $15 \mathrm{~m}$, by SCUBA and yabbie pump, coll. T. Naruse, Y. Fujita, Y. Endo \& N. Yoshitake, 16 Sep. 2015. Paratype, RUMFZC-5836, 1 female, $4.6 \times 8.7 \mathrm{~mm}$, same data as holotype.

\section{Comparative material}

See Naruse et al. (2017).

\section{Description}

Carapace (Fig. 1) trapezoidal, CW 1.89-1.94 times CL, dorsal surface convex strongly longitudinally, weakly transversely, smooth, regions indiscernible. Front sloping downwards, medially concave in dorsal view but ventrally produced to triangular lobe, forming part of interantennular septum in frontal view. Supra-, infraorbital margins entire, mesial end of infra- orbital margin forming triangular inner orbital tooth; lower part of suborbital and entire pterygostomial and hepatic regions granulated, setose, anteromesial part of pterygostomial region with obliquely arranged costae (Fig. 2). Milne-Edwards' opening distinct (Fig. 2). External orbital corner not angular, anterolateral margin confluent to orbit just below external orbital corner; anterolateral margin entire, convex anterolaterally, posterolateral margin slightly concave anteriorly, divergent posteriorly. Posterior margin long, lateral ends roundly concave, accommodating small condyle of thoracic sternite 7 (Fig. 1).

Epistome posterior margin forming wide concave curvature, with weak median projection.

Basal antennular article set transversely. Antennal articles set obliquely, entering into orbit. 


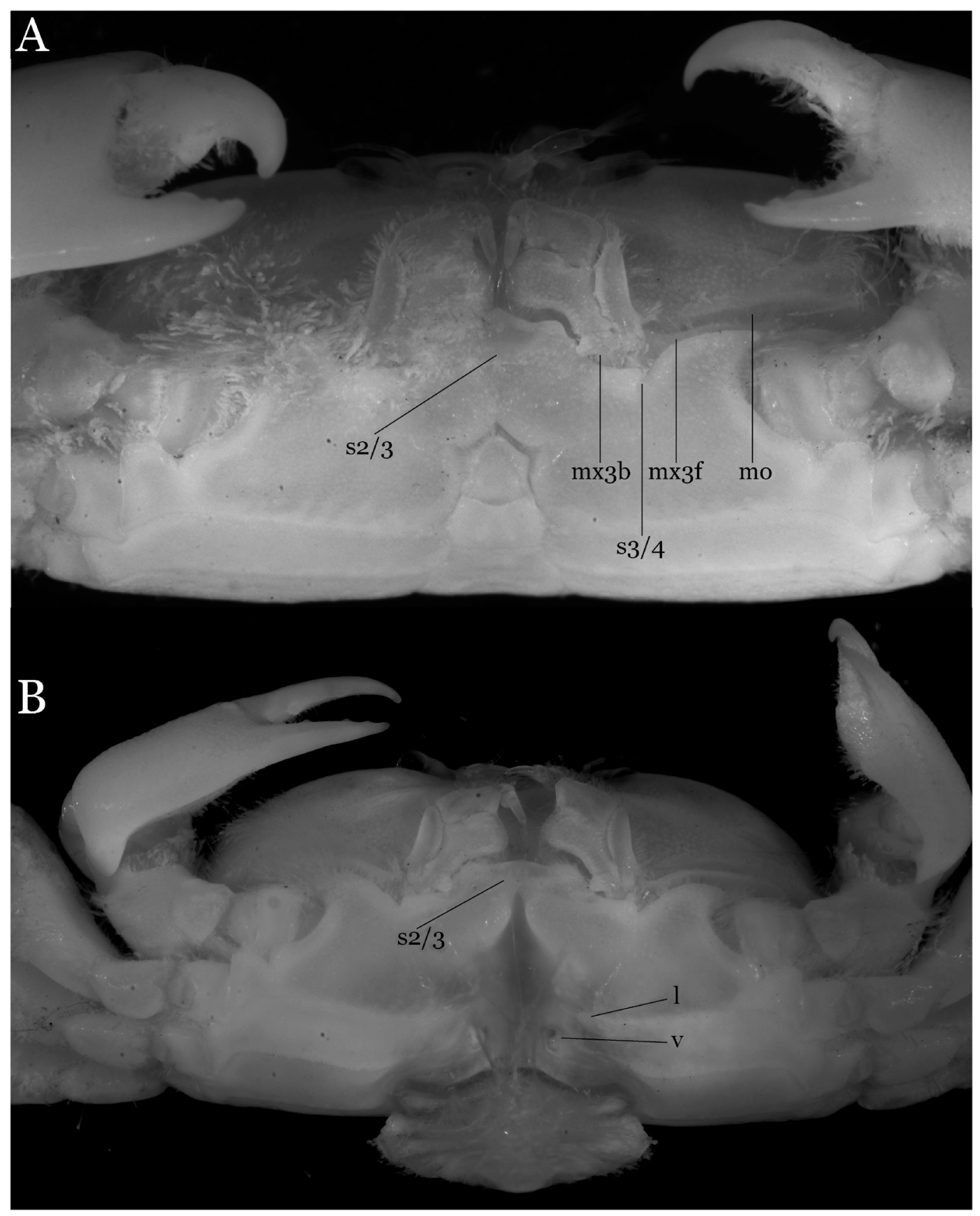

Fig. 2. Anteroventral view of cephalothorax of Hexapinus patuma, new species. A, holotype male, RUMF-ZC-5835, $4.9 \times 9.5 \mathrm{~mm}$; B, paratype female, RUMF-ZC-5836, $4.6 \times 8.7 \mathrm{~mm}$. Abbreviations: 1, pleonal locking mechanism; mo, Milne Edwards' opening; $\mathrm{mx} 3 \mathrm{~b}$, basis of third maxilliped; mx3f, flagellum of third maxilliped; s2/3, suture between thoracic sternites 2 and 3; s3/4, suture between thoracic sternites 3 and 4; v, vulva. 


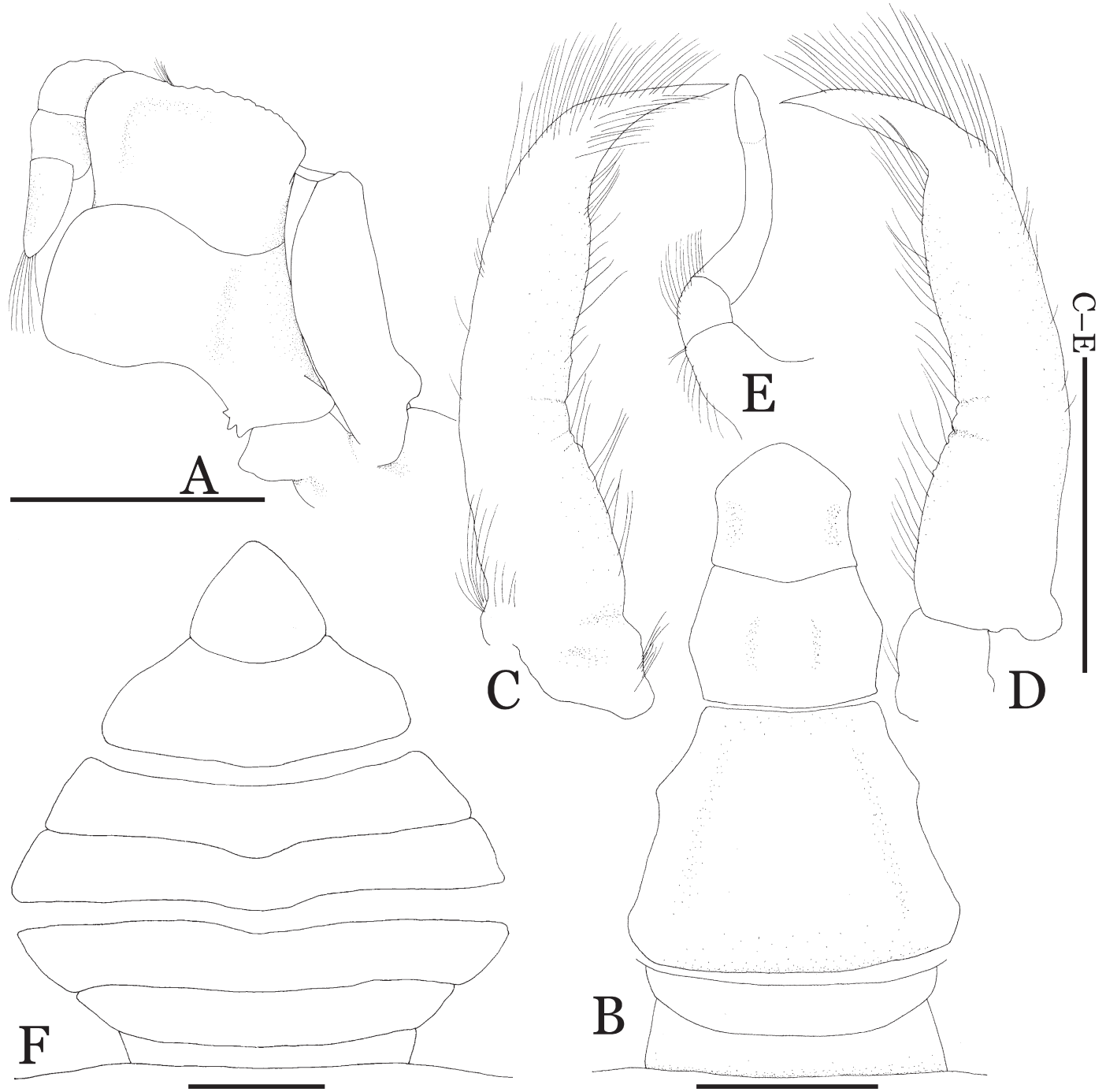

Fig. 3. Hexapinus patuma, new species. A-E, holotype male, RUMF-ZC-5835, $4.9 \times 9.5 \mathrm{~mm}$; F, paratype female, RUMFZC-5836, $4.6 \times 8.7 \mathrm{~mm}$. A, third maxilliped, left (setae are partially drawn); B, male pleon and posterior margin of carapace (setae are not drawn); C, G1, left, ventral view; D, G1, left, dorsal view; E, G2, left, dorsal view; F, female pleon and posterior margin of carapace (setae are not drawn). Scales: $1 \mathrm{~mm}$.

Eyes relatively short, small, mobile.

Mxp3 (Figs. 2, 3A) covering almost entire buccal cavern. Basis with triangular projection mesially. Ischium short, shorter than merus, posterior margin strongly concave, mesial margin strongly protruded, border with merus sinuous. Merus forming parallelogram. Palp long, dactylus longest among palp segments, reaching posterior to proximal half of mesial margin of ischium when folded. Exopod stout, mesial margin strongly convex, with long flagellum.

Chelipeds of both sexes (Fig. 1) short, relatively stout, stronger, asymmetric in male, subequal in female. Right cheliped of male holotype (Figs. 1A, 4A) larger than that of left (Figs. 1A, 4B). Male chelipeds merus short, trigonal in cross-section, carpus rhomboidal, inner corner blunt, no tooth, upper surface 


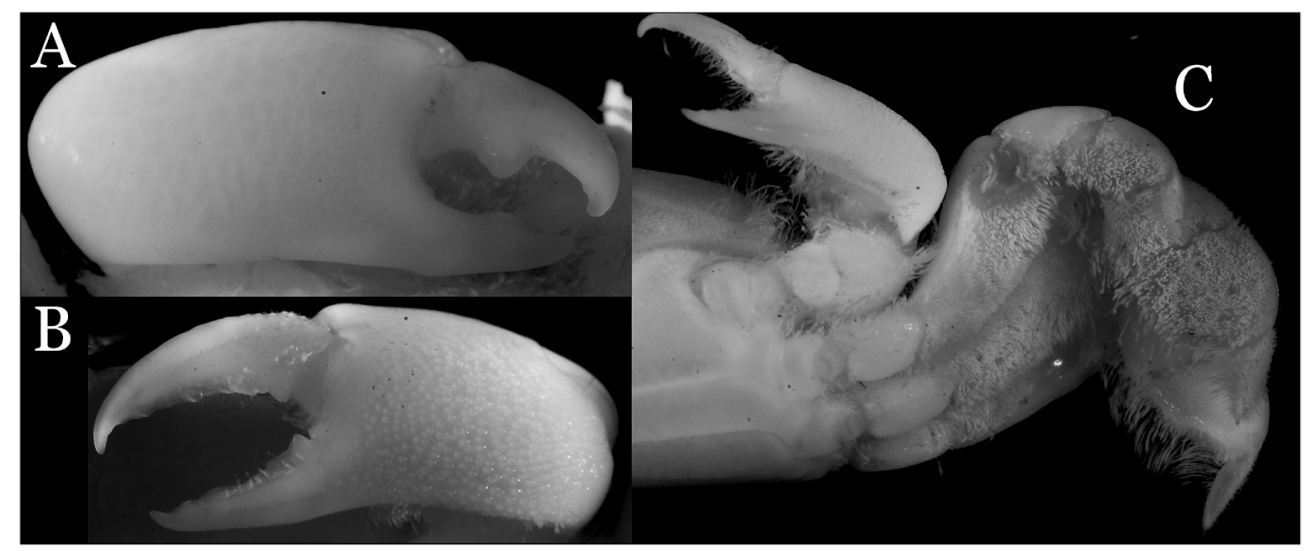

Fig. 4. Hexapinus patuma, new species. Holotype male, RUMF-ZC-5835, 4.9 $9.5 \mathrm{~mm}$. A, right major chela; B, left minor chela; $\mathrm{C}$, lower side of pereopods, showing mats of velvety setae. A and B are isometric.

smooth; inner margins of merus, carpus lined with setae; chela outer surface smooth, setose on upper half of inner surface of palm and inner surface of movable finger and base of immovable finger. Male major chela (Fig. 4A) with proportionally longer palm than minor chela, fingers tip pointed; immovable finger occlusal margin with low, wide, rounded submedial tooth, subproximal tooth very small; movable finger strongly curved downward distally, occlusal margin with triangular tooth submedially; minor chela (Fig. 4B) with pointed fingers tip; immovable finger occlusal margin with two small teeth subproximaly, followed distally by low lamellar blade; movable finger occlusal margin similar to that of immovable finger, except for absence of second subproximal tooth. Female chelal fingers similar to those of male minor chela.

Ambulatory legs (Figs. 1, 4C) relatively short, stout, P3 longest; mat of velvety setae present on following parts of P2-4 (Fig. 4C): P2 merus flexor surface (except for distomedian part near articulation with carpus) to flexor side of posterior surface, carpus flexor surface, propodus flexor surface to flexor side of anterior surface, P3 merus flexor surface (except for distomedian part near articulation with carpus) to flexor side of posterior surface, carpus flexor surface to almost entire anterior surface, propo- dus and dactylus flexor surface to entire anterior surface, P4 proximal half of flexoanterior margin; P4 carpus to dactylus flexor margin lined with long setae. Merus subrectangular; carpus, propodus short, both subtriangular; dactylus acicular, extensor margin straight, terminated in corneous claw.

Male thoracic sternites 1, 2 (Fig. 2A) fused, triangular, medially depressed; sternites 2, 3 demarcated by thick ridge, laterally produced anteriorly; sternites 3, 4 fused medially, demarcated only by lateral notches; sternites 4-7 very wide; sternopleonal cavity narrow, sternites 4-7 fused medially, no suture meeting medially, cavity reaching to level of about proximal third of bases of cheliped coxae, anteriorly and anterolaterally with 1 longitudinal and 1 pair of oblique grooves, respectively, tip of G1 visible from oblique groove even when pleon closed; pleonal locking button present on suture 4/5 at lateral slope of cavity; lateral margins of cavity sinuous, anterolateral corner of sternite 5, 6 produced, corresponding to lateral projection of pleonal somites 6,5 , respectively. Penis sternal. Female sternopleonal cavity (Fig. 2B) continued anteriorly as narrow groove as far as sternite 3; anterolateral part at pleonal cavity of sternite 5 with triangular projection, functioning as pleonal locking mechanism; vulva (Fig. 2B) semicircular, directed mesio- 
ventrally.

Male pleon (Figs. 2A, 3B) narrow; somites 1, 2 short; somites 3-5 fused, laterally produced on proximal fifth and distal third; somite 6 laterally produced on proximal half; telson subpentagonal, lateral margin concave, distally rounded. G1 (Fig. 3C, D) relatively stout, gently curved outward, distal part abruptly bent outward, tapering to sharp tip. G2 (Fig. 3E) small, distal segment narrow, long.

Female pleon (Fig. 3F) spade-like, all somites free; somites 3, 4 widest; somite 6 longest, laterally convex on proximal half, inner side of this convex part with socket for spade like projection of sternite 5; telson subtriangular; proximal parts of both endopod and exopod of pleopod directed mesiodistally, distal parts bent anteriorly, distal part of pleopods partially accommodated in anterior groove of sternopleonal cavity.

\section{Colouration}

The new species is wholly ivory-coloured, with slightly darker setae and reddish eyes (Fig. $1)$.

\section{Etymology}

The name of the new species is derived from the type locality, Patuma (= Hatoma in standard Japanese). The name is used as a noun in apposition.

\section{Habitats}

Two specimens of the new species were collected using a yabbie pump from burrow(s) on fine sandy bottom of depth of about $15 \mathrm{~m}$ within a fringing reef lagoon. It is uncertain whether the male and female were collected from a single burrow or not.

\section{Remarks}

Rahayu \& Ng (2014) redefined the genus Hexapinus Manning \& Holthuis, 1981, with the following characters: short and distally expanded mxp3 ischium with a strongly convex mesial margin, relatively shorter and stouter P2-4, and distinctively more slender and elongate male pleon. Rahayu \& Ng's (2014) male characters are mainly based on that of $\mathrm{H}$. simplex Rahayu \& Ng, 2014, which are subsequently confirmed by the examination of a male specimen of $H$. latipes (De Haan, 1835) (see Ng \& Rahayu, 2015), the type species of the genus. The $\mathrm{G} 1$ of $H$. latipes and $H$. simplex are similar in their slender and gently outwardcurved shape throughout the length $(\mathrm{Ng} \& \mathrm{Ra}-$ hayu, 2015: fig. 6A, B; Rahayu \& Ng, 2014: fig. 21A, B). The G1 of Hexapinus patuma, new species, is very different from those of $H$. latipes and $H$. simplex in its stout appearance with the distal part abruptly bent (Fig. 3C, D). The new species, however, shares all diagnostic characters of the genus, especially the characteristic mxp3 ischium. Members of Hexapi$n u s$, however, appear to have a relatively large variation in the shape of the G1. This is also the case with Mariaplax Rahayu \& Ng, 2014.

Hexapinus patuma, new species, is morphologically most similar to $H$. latus Rahayu \& $\mathrm{Ng}, 2014$, in its proportionally wide carapace with smooth dorsal surface (Rahayu \& Ng, 2014: fig. 16A; Ng \& Rahayu 2015, fig. 1C). The new species, however, can be easily distinguished from $H$. latus by its proportionally even wider carapace (CW 1.89-1.94 times CL versus 1.62-1.74 times), strong concavity on the posterior margin of mxp3 ischium (versus gently convex in $H$. latus), and the presence of mats of velvety setae on mainly P2-4 flexor surfaces (versus absent in $H$. latus). There is much sparser setation on the P2-4 flexor surfaces in $H$. latus (Rahayu \& $\mathrm{Ng}$, 2014: fig. $16 \mathrm{~B})$, but is not as dense as seen in the new species (Fig. 4C) (Dwi Listyo Rahayu, pers. comm.).

\section{Acknowledgements}

Thanks are due to Dwi Listyo Rahayu (Research Center for Oceanography-Indonesian 
Institute of Sciences (LIPI), Indonesia) for confirming the morphological characters of Hexapinus latus; and to Peter K. L. Ng (Lee Kong Chian Natural History Museum, National University of Singapore) and Akira Asakura (Seto Marine Biological Laboratory, Kyoto University) for reviewing the manuscript.

\section{$\square$ Literature Cited}

Haan, W. de (1835) Crustacea. Fauna Japonica, sive Descriptio animalium, quae in itinere per Japoniam, jussu et auspiciis superiorum, qui summum in India Batava imperium tenent, suscepto, annis 1823-1830 collegit, notis, observationibus et adumbrationibus illustravit P. F. de Siebold. Conjunctis studiis C. J. Temminck et H. Schlegel pro Vertebratis atque W. de Haan pro Invertebratis elaborata Regis aupicus edita. P. F. v. Siebold. Leiden, Lugundi-Batavorum. Decas II, 2564, pls. 9-15, 17, C, D.

Manning, R. B., \& Holthuis, L. B., 1981. West African brachyuran crabs (Crustacea: Decapoda). Smithsonian Contributions to Zoology, 306: 1-379.

Matsuo, M., 1971. On the larval development of Lambdophallus anfractus Rathbun (Goneplacidae, Hexapodinae). Researches on Crustacea, 4/5: 75-91. (In Japanese figure captions and résumé)

Naruse, T., Watanabe, T., \& Yoshida, R., 2017. Additional information on the distribution and habitats of six hexapodid species (Crustacea: Decapoda: Brachyura), with review of their Japanese names. Fauna Ryukyuana, 35: 17-28. (In Japanese with English abstract and figure captions)

Ng, P. K. L., \& Rahayu, D. L., 2015. Notes on Hexapodidae (Crustacea, Brachyura) from Indonesia and Malaysia, with description of a new species of Mariaplax Rahayu \& Ng, 2014, from Lombok, Indonesia. Zootaxa,
3981(1): 125-137.

Ng, P. K. L., \& Wong, K. J. H., 2019. The Hexapodidae (Decapoda, Brachyura) of Hong Kong, with description of a new species of Mariaplax Rahayu \& Ng, 2014. Crustaceana, 92(2): 233-245.

Rahayu, D. L., \& Ng, P. K. L., 2014. New genera and new species of Hexapodidae (Crustacea, Brachyura) from the Indo-West Pacific and east Atlantic. Raffles Bulletin of Zoology, 62: 396-483.

Rahayu, D. L., \& Widyastuti, E., 2018. Additions to the Indonesian crab fauna of the genus Mariaplax Rahayu \& Ng, 2014, and notes on Hexapus timika Rahayu \& Ng, 2014 (Crustacea, Decapoda, Brachyura, Hexapodidae). Zootaxa, 4379(2): 231-246.

Sakai, T., 1939. Studies on the crabs of Japan. IV. Brachygnatha, Brachyrhyncha. pp. 365-741, pls. 42-111. Yokendo Co., Tokyo.

Sakai, T., 1965. Notes from the carcinological fauna of Japan. (II). Researches on Crustacea, 2: 37-46, figs 1, 2, pls 5, 6, frontispieces 2, 3. (In Japanese and English)

Sakai, T., 1976. Crabs of Japan and the adjacent Sea. [In 3 volumes: (1) English text, (2) Plates volume, (3) Japanese text]. Kodansha, Tokyo.

Velip, D. T., \& Rivonker, C. U., 2014. Hexapus bidentatus sp. nov. (Crustacea: Decapoda: Brachyura: Hexapodidae), a new species from Goa, west coast of India. Marine Biology Research, 11(1): 97-105.

\section{Address}

(TN) Tropical Biosphere Research Center, Iriomote Station, University of the Ryukyus, 870 Uehara, Taketomi, Okinawa 907-1541, Japan.

\section{E-mail address}

(TN) naruse@lab.u-ryukyu.ac.jp 